\title{
Characterization of Natural Convection over an Elliptical Tubes Array AR 2.5 and PR 1.25 inside a Thermally Asymmetric Cavity of Various Clearance Ratio
}

\author{
Stefanus Lucky Surya Widhipratama ${ }^{1}$, Budi Utomo Kukuh Widodo ${ }^{2}$ * \\ ${ }^{1,2}$ Department of Mechanical Engineering, ITS, Sukolilo, Surabaya 60111, Indonesia \\ Received: 1 February 2018, Revised: 27 February 2018, Accepted: 17 March 2018
}

\begin{abstract}
Natural convection is the phenomenon of heat transfer due to buoyancy force of fluid. One application of natural convection inside a vertical cavity is refrigerator condenser of circular cross section tube. An experimental investigation is presented on natural convection of air over an array of elliptical tubes of $A R 2.5$ arranged vertically inside a thermally asymmetric cavity. One side of the cavity is insulated and the opposite side is exposed to ambient air. The distance between tubes, pitch ratio $(P R)$ is constant at 1.25 where "a" is a half of tube major axis. The Clearance Ratio $C R$ which is the ratio between the distance of tubes array major axis to the insulated wall $(x)$ and the width of the cavity $(y)$, is varied 0.4 and 0.6 . The heat flux of the tube is maintained at $22.79 \mathrm{~kW} / \mathrm{m}^{2}$. It is found that the higher value of heat transfer coefficient is achieved on $C R=0.4$.

Keywords: Natural Convection, Elliptical Tube, Thermally Asymmetric Cavity, Clearance Ratio, Pitch Ratio
\end{abstract}

\section{Introduction}

Natural convection is the phenomenon of heat transfer which occurs because of the natural motion of the fluid. The fluid flows vertically because of the buoyancy force which is affected by the density difference due to temperature difference. The parameters in the natural convection heat transfer are heat transfer coefficient $(h)$, heat transfer area $(A)$, and temperature difference.

One of the natural convection application is natural convection inside the vertical cavity. The cavity is shape of vertically oriented rectangle. Hence, buoyancy force direction is parallel to the vertical axis. The cavity is thermally asymmetric, where one side is insulated whilst the opposite is exposed to ambient air. The heat is generated by electrical heater inserted in the array of elliptical tubes.

The parameters of the characterization in this study are aspect ratio $(A R)$, Pitch Ratio $(P R)$, and Clearance Ratio $(C R)$. Aspect ratio is the ratio between major $(2 a)$ and minor $(2 b)$ axis of the tube. The value of $A R$ of circular tube equals 1 . The higher value of $A R$ results the smaller value of drag coefficient of fluid flow over the tube surface. Pitch ratio $(P R)$ is the distance between axis of two consecutive tubes to major axis while clearance ratio $(C R)$ is the ratio between the distance from axis of elliptical tubes array to insulated wall $(x)$ and the width of cavity $(y)$.

The experimental study of the natural convection over the tubes with various aspect ratio $(A R)$ has been conducted by H. M. Badr. This study varied $A R$ value onto 2.5 and 1 with the constant value of Prandtl number $(P r)$ which was 0.7. The result showed that the higher value of $A R$ results the higher value of heat transfer rate [1]. Utomo (2014) also conducted the experimental study about the forced convection over the tubes with various $A R$. It showed that the $A R$ value of 2.5 had better characterization of heat transfer compared to the $A R$ value lower than 2.5. The characterization of heat transfer over the tube with $A R 3$ corresponded to the characterization of heat transfer over the flat plate [2]. Moreover, Nabila Amelita Laelyani (2018) also conducted the similar experimental investigation to this study about the characterization of natural convection over the elliptical tubes array inside the thermally asymmetric cavity. The $A R$ value of tube and the pitch ratio $(P R)$ were constant at 2.5 and 1.5. The various $C R$ values of 0.4 and 0.6 were used to investigate the effect of $C R$ on the characterization of natural convection inside the cavity. The heat flux was maintained at constant value. It was found that the heat transfer coefficient of $C R 0.6$ was higher than that of $C R 0.4$ [3].

It can be seen from literature that limited studies have been conducted on elliptical tubes and it is therefore more experimental studies in this area of interest is still needed. This study uses three horizontally elliptical tube of $A R 2.5$ as bluff bodies which are arranged vertically inside a thermally asymmetric cavity with $P R$ value of 1.25 . The $C R$ value are varied 0.4 and 0.6 respectively. And the heat flux is maintained constant at $22.79 \mathrm{~kW} / \mathrm{m}^{2}$.

\footnotetext{
*Email:email: buditem@me.its.ac.id phone: +62 81520955877
} 
Table 1. List of Symbol

\begin{tabular}{|c|c|c|}
\hline \multicolumn{3}{|c|}{ NOMENCLATURE } \\
\hline Symbol & Description & Unit \\
\hline $2 a$ & Tube Major Axis & $\mathrm{m}$ \\
\hline $2 b$ & Tube Minor Axis & $\mathrm{m}$ \\
\hline$A$ & Heat Transfer Area & $\mathrm{m}^{2}$ \\
\hline$\overline{A R}$ & Major and Minor Axis Ratio, 2a/2b & \\
\hline$C R$ & Clearance Ratio, $\mathrm{x} / \mathrm{y}$ & \\
\hline$g$ & Gravitational Acceleration & $\mathrm{m} / \mathrm{s}^{2}$ \\
\hline$H$ & Cavity Height & $\mathrm{m}$ \\
\hline$h$ & Heat Transfer Coefficient & $\mathrm{kW} / \mathrm{m}^{2} \mathrm{~K}$ \\
\hline $\bar{h}_{L}$ & Average Heat Transfer Coefficient Based on $L$ & $\mathrm{~kW} / \mathrm{m}^{2} \mathrm{~K}$ \\
\hline$I$ & $\begin{array}{l}\text { Electric Current } \\
\end{array}$ & $\mathrm{A}$ \\
\hline$k$ & Thermal Conductivity & $\mathrm{W} / \mathrm{mK}$ \\
\hline$L$ & The Distance Between Tubes Array to Uninsulated Wall & $\mathrm{m}$ \\
\hline $\bar{N} u_{L}$ & Average Nusselt Number Based on $L$ & \\
\hline$P R$ & Pitch Ratio, The Distance Between Center of Tube / Tube Major Axis & \\
\hline $\operatorname{Pr}$ & Prandtl Number & \\
\hline q" & Heat Flux & $\mathrm{kW} / \mathrm{m}^{2}$ \\
\hline$R a_{L}$ & Average Rayleigh Number Based on $L$ & \\
\hline$\overline{T_{f}}$ & Average Film Temperature & K \\
\hline $\bar{T}_{s}$ & Average Tube Surface Temperature & K \\
\hline $\bar{T}_{w}$ & Average Uninsulated Wall Temperature & $\mathrm{K}$ \\
\hline$V$ & Voltage & $\mathrm{V}$ \\
\hline$x$ & The Distance Between Tubes Array to Insulated Wall & $\mathrm{m}$ \\
\hline$y$ & Cavity Width & $\mathrm{m}$ \\
\hline \multicolumn{3}{|c|}{ GREEK } \\
\hline Symbol & Description & Unit \\
\hline$\alpha$ & Thermal Diffusivity & $\mathrm{m}^{2} / \mathrm{s}$ \\
\hline$\beta$ & Volumetric Thermal Expansion Coefficient, $1 / \bar{T}_{f}$ & $\mathrm{~K}^{-1}$ \\
\hline$\nu$ & Kinematic Viscosity & $\mathrm{m}^{2} / \mathrm{s}$ \\
\hline
\end{tabular}

\section{Experimental set up}

The object of this study is three horizontal elliptical copper tubes each of $43 \mathrm{~mm}$ major and $17 \mathrm{~mm}$ minor axis, arranged vertically. The tube length is $100 \mathrm{~mm}$. The electric heater is placed inside and exactly on the center of each tube. Each tube is filled by metal powder to conduct heat from heater to tube surface. The installation of electric heater and elliptical tube is shown in Figure 1 . To control the heating process, a thermo-controller is used. Elliptical tubes array is placed inside a rectangle cavity with the particular distance to the insulated wall $(x)$. The cavity is made from transparent acrylic with melting point of $160^{\circ} \mathrm{C}$. The dimensions of the cavity are $100 \mathrm{~mm}$ in length, $100 \mathrm{~mm}$ in width $(y)$, and $225 \mathrm{~mm}$ in height $(H)$. To measure the temperature, type $\mathrm{K}$ thermocouple wires are used. Six thermocouple wires are installed on the surface of each tube, ten inside the cavity, and three on the uninsulated wall. The left side of the cavity wall is insulated by $25 \mathrm{~mm}$ thick polyurethane foam covered by aluminum foil. The dimension of the cavity and the temperature measurement points are shown in Figure 2 .

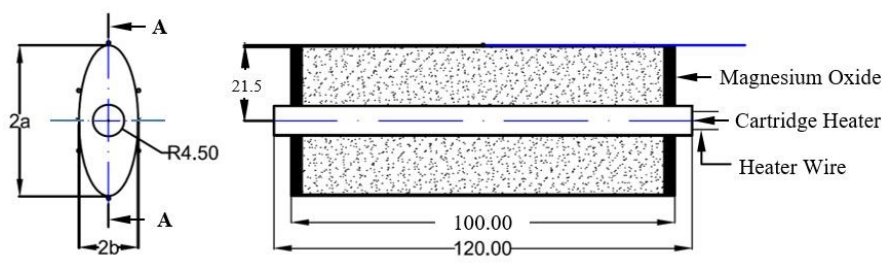

Figure 1. The Installation of Elliptical Tube and Electric Heater 


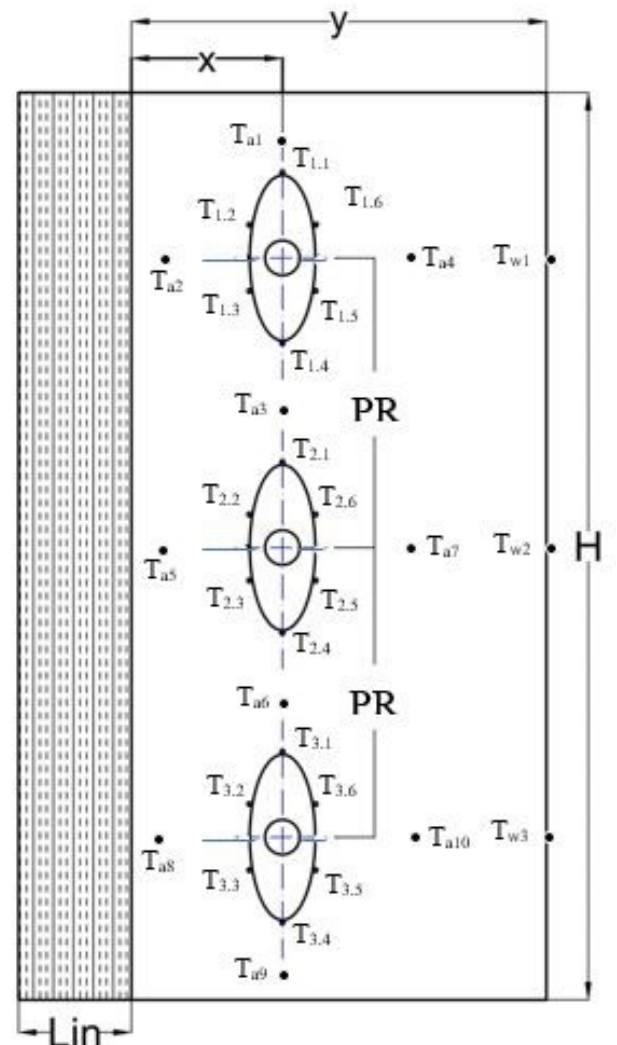

Figure 2. Temperature Measurement Points

Data acquisition is executed by Arduino microcontroller and PLX-DAQ software, and the temperature data is exhibited on Microsoft Excel worksheet. The acquired temperature data is then analyzed and used to obtain the average heat transfer coefficient. The average heat transfer coefficient is defined as:

$$
\overline{h_{L}}=\frac{N \bar{u}_{L} k}{L}
$$
[4]:

where the average Nusselt number is obtained as

$$
\bar{N} u_{L}=0,22\left(\frac{P r}{0,2+\operatorname{Pr}} \operatorname{Ra}_{L}\right)^{0,28}\left(\frac{H}{L}\right)^{-\frac{1}{4}}
$$

where $H=225 \mathrm{~mm}$ and $L=60 \mathrm{~mm}$ for $C R 0.4$ and $40 \mathrm{~mm}$ for $C R$ 0.6. The average Rayleigh number above is defined as [4]:

$$
\operatorname{Ra}_{L}=\frac{g \beta\left(\bar{T}_{s}-\bar{T}_{w}\right) L^{3}}{v \alpha}
$$

where $\bar{T}_{s}$ is the average temperature of tubes surface and $\bar{T}_{w}$ is the average temperature of uninsulated wall. The thermo physical properties, Prandtl number $(P R)$, kinematic viscosity $(\nu)$, thermal diffusivity $(\alpha)$, and thermal conductivity $(k)$ are estimated at the film temperature, $\bar{T}_{f}$, which is defined as:

$$
\bar{T}_{f}=\frac{\bar{T}_{s}+\bar{T}_{w}}{2}
$$

The average heat transfer coefficient is also obtained from the heat flux:

$$
\bar{h}_{L}=\frac{q "}{\bar{T}_{s}-\bar{T}_{w}}
$$

where heat flux ( $q$ ”) is originated from electrical heater:

$$
q "=\frac{V . I}{A}
$$

where $V$ is the electrical potential, $I$ is the current which passes through each tube, and $A$ is the surface area of the tube.

\section{Results and Discussion}

3.1. Temperature Distribution on the Elliptical Tube Surface

The surface temperature distributions on elliptical tube at constant heat flux are plotted on Figure 3 . It can

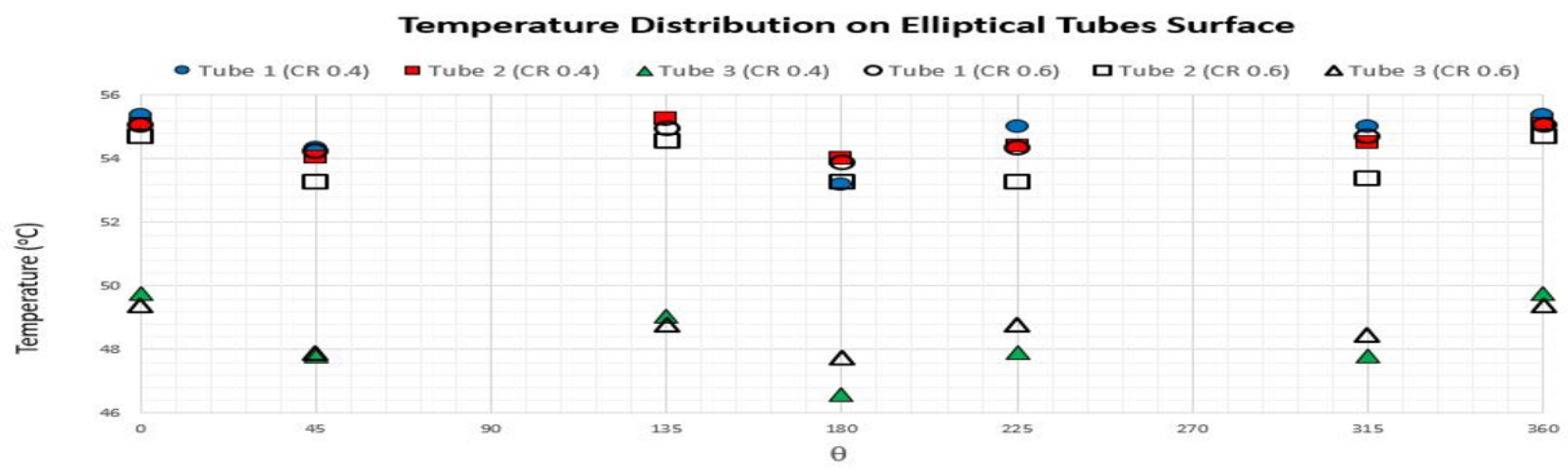

Figure 3. Temperature Distribution Around the Elliptical Tubes 
be seen from the Figure 3 that on all value of $C R$, the temperatures on the left region of tubes tend to be higher than those on the right region. It is due to the existence of the insulated wall on the left region of tubes which makes the heat is more difficult to be transferred. Other phenomenon that can be seen from Figure 3 is the temperatures on $C R 0.4$ tend to be higher than those on $C R$ 0.6 .

It is because the elliptical tubes array on $C R 0.4$ is closer to the insulated wall on the left region compared to that on CR 0.6. Furthermore, the temperatures of higher located tubes are higher than those of the lower ones $\left(\bar{T}_{\text {tube } 1}>\bar{T}_{\text {tube } 2}>\bar{T}_{\text {tube } 3}\right)$. It is because the fluid flows over the tube number one is already heated by tube number two and number three consecutively. The fluid flows over the tube number three is not affected by anything (free flow). This phenomenon also ensures that the temperature at point 4 on each tube is the lowest.

\subsection{Average Heat Transfer Coefficient}

The comparison of the average heat transfer coefficient between two approaches on $C R 0.4$ and $C R 0.6$ is plotted on Figure 4. It can be seen from Figure 4 that regardless the bases of the calculation, the average heat transfer coefficient on $C R 0.4$ tends to be higher than that on $C R$ 0.6. It is because the temperature difference between elliptical tubes array and uninsulated wall on $C R$ 0.4 is lower than that on $C R 0.6$. It can be seen at equation (5). Also, from the equation (3), it shows that the higher value of $L$ results a higher value of average Rayleigh number. The value of $L$ on $C R 0.4$ is higher than that on $C R$ 0.6. Other than that, the average heat transfer coefficient based on equation (1) tends to be higher than that of heat flux based. This difference is due to the different parameters used on those two approaches. But the heat transfer coefficient based on the heat flux is more relevant because all parameters used are obtained from measurement.

\section{Average Heat Transfer Coefficient between Approaches on CR 0.4 and 0.6}

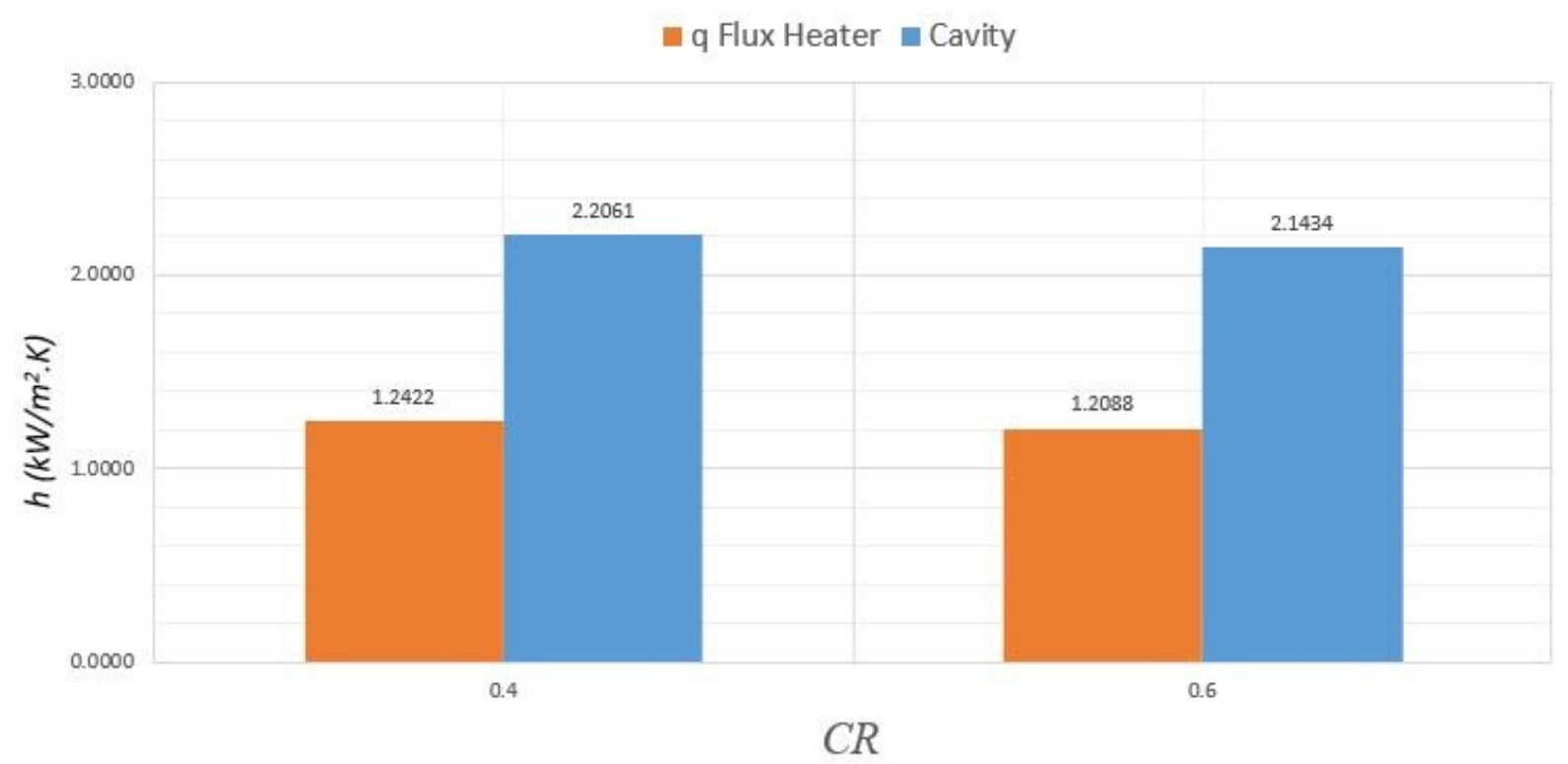

Figure 4. Average heat transfer coefficient between approaches on $C R 0.4$ and 0.6

\section{Conclusions}

Natural convection over the elliptical tubes array inside the thermally asymmetric cavity has been investigated experimentally. The average heat transfer coefficient has been presented at different clearance ratio $(C R)$ at constant heat flux. It is found, the temperatures on the left region of tubes tend to be higher than those on the right region. This phenomenon also occurs vertically. The temperatures tend to be higher on the elliptical tube at the top compared to those at the lower and at the bottom. And the average heat transfer coefficient tends to be higher on the smaller $C R$ value ( $C R$ 0.4) compared to that of higher CR (CR 0.6).

\section{Acknowledgments}

The authors wish to acknowledge the support received from Department of Mechanical Engineering, Institut Teknologi Sepuluh Nopember during this study. The authors also would like to thank the ITS Research and Community Service Institute for funding this study. 


\section{References}

[1] H. Badr, "Laminar natural convection from an elliptic tube with different orientations," Journal of heat transfer, vol. 119, no. 4, pp. 709-718, 1997.

[2] B. U. K. WIDODO, Studi Eksperimental Perpindahan Kalor dan Penurunan Tekanan Aliran Udara Melintasi Penukar Kalor Kompak Tabung Eliptik Susunan Berseling. PhD thesis, Department of Mechanical and Industrial Engineering, Universitas Gadjah Mada, 2014.
[3] N. A. Laelyani, Characterization of Natural Convection over an Elliptical Tubes Array inside Asymmetrical Thermal Cavity with the Variation of $A R=2.5 ; C R=$ $0.4 \& 0.6$; Tref $=550 C, 650 C, \& 75 o C$ with $P R=3 a$. $\mathrm{PhD}$ thesis, Department of Mechanical Engineering, Institut Teknologi Sepuluh Nopember, 2018.

[4] F. P. Incropera, A. S. Lavine, T. L. Bergman, and D. P. DeWitt, Fundamentals of heat and mass transfer. Wiley, 2007. 